\title{
Understanding the Solution Chemistry of Lead Halide Perovskites Precursors
}

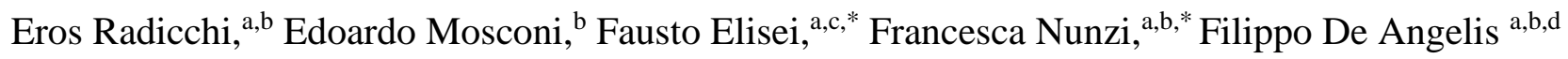

${ }^{a}$ Department of Chemistry, Biology and Biotechnology, University of Perugia, via Elce di Sotto 8, I-06123 Perugia, Italy.

${ }^{\mathrm{b}}$ Computational Laboratory of Hybrid/Organic Photovoltaics (CLHYO), CNR-ISTM, via Elce di Sotto 8, I06123 Perugia, Italy.

${ }^{\mathrm{c}}$ Center of Excellence on Innovative Nanostructured Materials (CEMIN), University of Perugia, via Elce di Sotto, 8, I-06123 Perugia, Italy.

${ }^{\mathrm{d}}$ CompuNet, Istituto Italiano di Tecnologia, Via Morego 30, 16163 Genova, Italy.

Corresponding Author*E-mail: fausto.elisei@unipg.it; francesca.nunzi@unipg.it

KEYWORDS: iodoplumbates; DMSO; DMF; DFT; TD-DFT; UV-Vis; solar cells 


\begin{abstract}
Identifying the composition of the solvated iodoplumbate complexes that are involved in the synthesis of perovskites in different solution environments is of great relevance in order to link the type and quantity of precursors to the final optoelectronic properties of the material. In this paper we clarify the nature of these species and the involved solution equilibria by combining experimental analysis and high-level theoretical calculations, focusing in particular on the DMSO and DMF solvents, largely employed in the perovskites synthesis. The specific molecular interactions between the iodoplumbate complexes, $\left[\mathrm{PbI}_{\mathrm{m}}\right]^{2-\mathrm{m}}$, and the solvent molecules, $\mathrm{X}$, were analyzed by identifying the most thermodynamically stable structures in various solvent solutions and characterizing their optical properties trough DFT and TD-DFT calculations. A comparison with the experimental UV-Vis absorption spectra allows for the first time the definition of the number of iodide and solvent ligands bonded to the $\mathrm{Pb}^{2+}$ ion and of the complex formation constants of the involved species.
\end{abstract}




\section{Introduction}

Lead halide perovskites (LHPs) show outstanding optoelectronic properties, that have allowed the production of highly efficient solar cells, ${ }^{1-3}$ rivaling with established technologies. A significant point of strength for LHPs is that they can be efficiently synthesized by cheap solution-based methods, ${ }^{4-8}$ starting from common materials, such as $\mathrm{PbI}_{2}$ and methylammonium iodide (MAI) in an appropriate coordinating solvent, typically dimethylsulfoxide (DMSO), dimethylformamide (DMF), $\gamma$-butyrolactone (GBL), acetonitrile (ACN) or a combination thereof.

The basic LHPs synthesis is surprisingly simple: mixing a metal-halide precursor solution (e.g. a concentrated solution of $\mathrm{PbI}_{2}$ ) with a 1:1 halide salt containing the A-cation (e.g. MAI) and evaporating the solvent gives a polycrystalline $\mathrm{MAPbI}_{3}$ thin film, Eq. 1:

$$
\left[\left(\mathrm{PbI}_{2}\right)-\text { solv }_{\mathrm{n}}\right]_{\text {solv }}+(\mathrm{MAI})_{\text {solv }} \rightarrow\left(\mathrm{MAPbI}_{3}\right)_{\text {solid }}+\operatorname{solv}_{\text {gas }}
$$

The apparent simplicity of the synthesis, however, should not be taken as the underlying physicochemical processes being similarly simple, since they involve the solvation/desolvation and complexation equilibria of all the participating species. Many variables have to be taken into account when dealing with these solution-based synthesis methods. It has been proven that changing any synthesis parameter, such as the precursors concentration and stoichiometry, and the nature of the solvent may lead to perovskites with different structural, electronic and optical properties, that finally affect the ensuing solar cell efficiency and stability. ${ }^{9-26}$ A plethora of different approaches have been implemented to improve the quality of the perovskite thin films, including change of the precursor stoichiometry, ${ }^{9}$ use of different lead salts, ${ }^{10}$ change of the halide ${ }^{11,12,21-23}$ and use of solvent engineering tecnhiques. ${ }^{13-15,24-26}$

The nature of the solvent can affect the final material quality both in terms of crystallization rate and formation of solid state intermediates from the precursors, which have been characterized by means of X-ray powder diffraction and other structural analysis in $\mathrm{DMSO},{ }^{24,27} \mathrm{DMF}^{28,29}$ and 
$\mathrm{GBL}^{30}$ solvents. Moreover, some synthetic routes for highly efficient perovskites employ antisolvents $^{31,32}$ (e.g. chlorobenzene or toluene) and the treatment of precursors solution with additives, such as hexamethylphosphoramide ${ }^{33}$ and 1,3-dimethyl-2-imidazolidinone, ${ }^{34}$ as well as the use of solvent blends. ${ }^{35}$ Various studies have been carried out on the solution chemistry of the perovskite precursors, ${ }^{16,36-45}$ highlighting the primary role of the coordinating solvent in the formation of iodoplumbate species in typical synthetic solution environment. Nevertheless, no clear evidence of the specific structures of the solvated iodoplumbate is provided, rather a sort of correlation between specific solvent properties (e.g. dielectric constant, polarity, Gutmann's donor ability, Mayer bond order, coordinative power) and feasible iodoplumbate complexes are generally supplied. At present the nature of the iodoplumbate species formed in the perovskite precursor solution, specifically the coordination number of the possible $\mathrm{Pb}^{2+}$ complexes, in terms of both iodide and solvent coordinated ligands, and the selective role of different coordinating solvents has not been fully understood.

Accordingly, in the present manuscript we investigate the chemistry of typical precursor solutions employed for LHPs synthesis by a combined experimental and computational approach. In particular, we study the properties of both $\mathrm{Pb}\left(\mathrm{NO}_{3}\right)_{2}$ and $\mathrm{PbI}_{2}$ solutions in $\mathrm{DMSO}$, without and with the addition of MAI, and we then extend the same analysis to a $\mathrm{PbI}_{2}$ solution in $\mathrm{DMF}$. By comparing the calculated energetics and UV-Vis spectra of several possible intermediates, $\left[\mathrm{PbI}_{\mathrm{m}} \mathrm{X}_{\mathrm{n}}\right]^{2-\mathrm{m}}(\mathrm{X}=\mathrm{DMSO}, \mathrm{DMF})$, to the experimental absorption profiles of different solutions with and without added MAI, we identify, for each solvent, the species effectively involved in the perovskite precursor solution, characterizing the iodide and solvent coordination number and the structural and optical properties. A general trend based on the coordinative power of different solvents in forming different iodoplumbates is obtained. Our results show how the solvent profoundly affects the nature of the LHP precursor solution, in terms of lead coordination number 
and stability of different solvent/halide lead complexes, possibly providing important information on how to further optimize the perovskite synthetic conditions.

\section{Methods}

\subsection{Computational details}

We investigate a series of $\left[\mathrm{PbI}_{\mathrm{m}} \mathrm{X}_{\mathrm{n}}\right]^{2-\mathrm{m}}$ complexes (where $\mathrm{m}=0-4, \mathrm{n}=0-7$, and $\mathrm{X}=\mathrm{DMSO}$, DMF, GBL, ACN). The molecular and electronic structure calculations were performed within density functional theory (DFT) using the Gaussian $09^{46}$ software package, using the LANL2DZ basis set for heavy $\mathrm{Pb}$ and also for I atoms together with the LANL2 pseudopotentials for the core electrons, while for light atoms $(\mathrm{C}, \mathrm{H}, \mathrm{N}, \mathrm{O}, \mathrm{S})$ we employed the 6-31G* basis sets. The ADF 2014.04 program package ${ }^{47-49}$ has been used for the time dependent (TD) DFT calculations together with a Slater type TZP basis set for all the atoms (the cores $1 \mathrm{~s}-4 \mathrm{p}$ and $1 \mathrm{~s}-4 \mathrm{~d}$ were kept frozen, respectively for I and $\mathrm{Pb}$ ) and a ZORA Hamiltonian to include relativistic spin-orbit coupling (SOC) effects. ${ }^{50,51}$ In both cases we recurred to the B3LYP exchange-correlation functional. ${ }^{52-55}$ Solvents considered in this work were simulated both with implicit solvation models (polarizable continuum model, PCM in Gaussian09 and COSMO in ADF 2014.04) and adding explicit coordinative molecules, that is necessary to investigate for the particular chemical interactions that we are interested in. The effect of the coordinative solvent on the various iodoplumbate complexes $\left[\mathrm{PbI}_{\mathrm{m}} \mathrm{X}_{\mathrm{n}}\right]^{2-\mathrm{m}}$ has been deeply investigated evaluating the energetics of the complexes for different solvents, using the following equation:

$$
E_{\text {rel }}=\frac{E_{t o t}-E_{i o d o}-E_{s o l v} * n}{n}
$$

where $E_{\text {tot }}$ is the total energy of the $\left[\mathrm{PbI}_{\mathrm{m}} \mathrm{X}_{\mathrm{n}}\right]^{2-\mathrm{m}}$ system, $E_{\text {iodo }}$ and $E_{\text {solv }}$ are, respectively, the energy of the unsolvated iodoplumbate $\left[\mathrm{PbI}_{\mathrm{m}}\right]^{2-\mathrm{m}}$ and of the solvent molecule $\mathrm{X}$, and $n$ is the number of explicit coordinating solvent molecules of X. 
The absorption spectra have been simulated by interpolating the computed electronic transitions by Gaussian functions with a broadening $\sigma=0.01 \mathrm{eV}$.

\subsection{Experimental details}

Solutions of $\mathrm{Pb}\left(\mathrm{NO}_{3}\right)_{2} 0.1 \mathrm{mM}$ in DMSO and $\mathrm{PbI}_{2} 0.24 \mathrm{mM}$ in DMF were prepared, while in GBL and ACN solvents we could not attain the lead salt dissolution. MAI solutions in DMF and in DMSO were prepared and added to the reaction container with a 2-20 $\mu \mathrm{L}$ and a $20-200 \mu \mathrm{L}$ Rainin Pipet-lite ${ }^{\mathrm{TM}}$ micropipette in order to obtain $\mathrm{Pb}$ :MAI mole ratio ranging from 1:2 to 1:152 / 1:1 to 1:150 in DMSO / DMF solvent. Moreover, $\mathrm{PbI}_{2}$ solutions with concentrations ranging from 0.05 to $0.50 \mathrm{mM}$ in DMSO were prepared. $\mathrm{PbI}_{2} 0.24 \mathrm{mM}+\mathrm{MAI}$ solutions in a 1:5 ratio were prepared both in GBL and ACN solvents in order to obtain the complete dissolution of the lead salt. Further MAI were added from a $0.1 \mathrm{M}$ solution with a 20-200 $\mu \mathrm{L}$ Rainin Pipet-lite ${ }^{\mathrm{TM}}$ micropipette. UV-Vis absorption spectra were recorded with a double beam spectrophotometer Perkin-Elmer Lambda 800 at each addition of MAI, employing quartz cuvettes with two optical walls and an optical path of 1.0 or $0.5 \mathrm{~cm}$. In order to determine the equilibrium constants as well as the concentration profiles and the spectra of intermediate species, the global fitting of multivariate spectrophotometric data was carried out by employing the ReactLab ${ }^{\mathrm{TM}}$ EQUILIBRIA $^{56}$ software (Jplus Consulting). The parameters sum-of-squares and deviation standard for the residuals were used to evaluate the goodness of the fits. $\mathrm{Pb}\left(\mathrm{NO}_{3}\right)_{2} 1 \mathrm{mM}$ in DMSO and $0.1 \mathrm{mM}$ in DMF were also prepared and added with MAI with different Pb:MAI mole ratio in order to supply data for a more complete EQUILIBRIA analysis.

\section{Results and Discussion}

It is well established that $\mathrm{Pb}^{2+}$ ions readily undergo complexation with halides ions and that coordinative solvents are able to donate a pair of electrons to form Lewis adducts with the metal 
centre. ${ }^{36}$ The coordinative solvents are expected to play a key role on the stabilization of the various iodoplumbates in the precursor solution. We first registered the UV-Vis absorption spectra of the $\mathrm{Pb}\left(\mathrm{NO}_{3}\right)_{2} / \mathrm{PbI}_{2}$ salts in DMSO / DMF solvents, to then examine the effect on the absorption spectra of the addition of MAI in different concentrations. The $\mathrm{PbI}_{2}$ salt is expected to dissociate in $\mathrm{PbI}^{+}$and $\mathrm{Pb}^{2+}$ ions, while upon incremental addition of $\mathrm{I}^{-}$in solution, it also equilibrates with various iodoplumbate species (e.g. $\mathrm{PbI}_{3}^{-}, \mathrm{PbI}_{4}{ }^{2-}$ ), giving rise to a complex solution chemistry. The measured UV-Vis spectra of $\mathrm{PbI}_{2}$ in DMSO (see Figure S2 and Table S2 in SI) confirm the dissociation of $\mathrm{PbI}_{2}$, according to the Lambert-Beer law. Therefore, in order to eliminate possible uncertainties on the starting solution composition, we decided to employ $\mathrm{Pb}\left(\mathrm{NO}_{3}\right)_{2}$ solutions as lead source. $\mathrm{Pb}\left(\mathrm{NO}_{3}\right)_{2}$ is completely dissociated into free ions in DMSO, based on the agreement of measured UV-Vis spectra with the Lambert-Beer law (see Table S1 in SI). The UV-Vis spectrum $\mathrm{Pb}\left(\mathrm{NO}_{3}\right)_{2}$ in DMSO (Figure 1a) shows one peak, centered at $257 \mathrm{~nm}$, that can be assigned to the solvated $\mathrm{Pb}^{2+}$ ion. By adding increasing concentration of MAI to the solution, the solvated $\mathrm{Pb}^{2+}$ peak slightly shifts and its intensity increases, while two new bands at 290 and $320 \mathrm{~nm}$ raise, thus pointing at the appearance of different iodoplumbate species, in agreement with Stewart et al. ${ }^{37}$. Further absorption spectra for $\mathrm{Pb}\left(\mathrm{NO}_{3}\right)_{2}$ solutions with different salt concentrations (i.e. 0.1 and 1 $\mathrm{mM}$ ) and with $\mathrm{Pb}: \mathrm{MAI}$ concentrations ratio beyond 1:152 were also registered. The overall data were analyzed for the definition of the spectral shapes and complex formation constants of the involved species. The equilibrium constants for the hypothesized $\left[\mathrm{PbI}_{m} \mathrm{X}_{n}\right]^{2-\mathrm{m}}$ complexes are reported in Table 1, showing that $\mathrm{PbI}^{+}$and $\mathrm{PbI}_{2}$ species are thermodynamically favored with respect to $\mathrm{PbI}_{3}{ }^{-}$and $\mathrm{PbI}_{4}{ }^{2-}$ both in DMSO and DMF solvents, even if with different magnitude: the formation of iodoplumbates with an high content of iodide is in fact favored in the less coordinative solvent. Since we could not elaborate the formation constant value of the $\mathrm{PbI}_{4}{ }^{2-}$ complex, we included in Table 1 the results from Manser et al., ${ }^{36}$ that agree pretty well with the reported $\mathrm{PbI}_{3}{ }^{-}$ formation constant value. The elaborated spectra, Figure S2 in SI, show that $\mathrm{PbI}^{+}$and $\mathrm{PbI}_{2}$ have a 
similar absorption maximum (287 vs $290 \mathrm{~nm}$ ), though the latter has a higher molar absorption coefficient. 

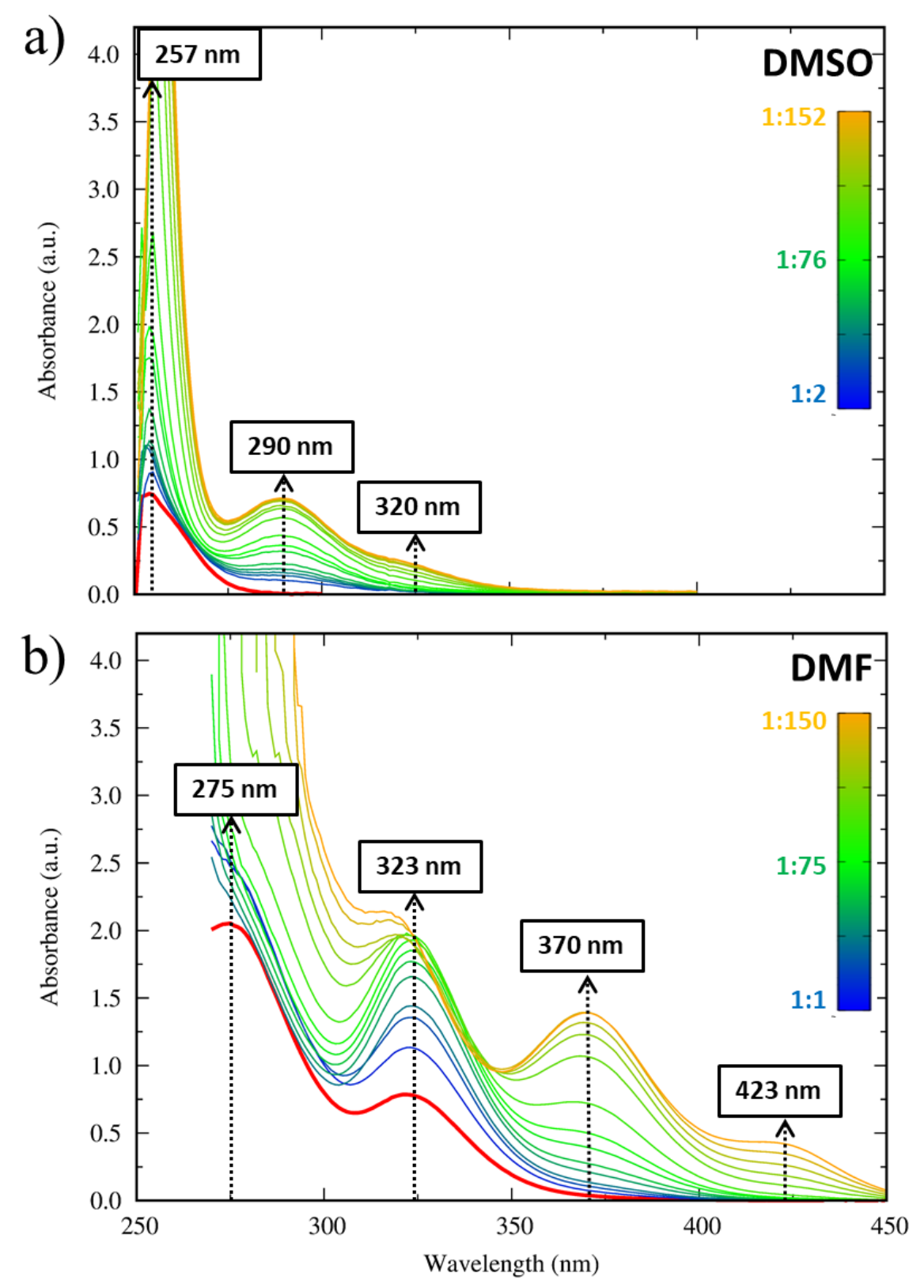

Figure 1. UV-Vis absorption spectra of a) solutions of $\mathrm{Pb}\left(\mathrm{NO}_{3}\right)_{2} 0.1 \mathrm{mM}$ in DMSO and b) $\mathrm{PbI}_{2}$ $0.24 \mathrm{mM}$ in DMF - red solid lines - and with increasing concentration of MAI - colored lines. Pb:MAI mole ratio from 1:2 to 1:152 in DMSO and from 1:1 to 1:150 in DMF. The arrows point at the absorption maxima positions. 
Table 1. Formation constants for the $\left[\mathrm{PbI}_{\mathrm{m}} \mathrm{X}_{\mathrm{n}}\right]^{2-\mathrm{m}}$ complexes hypothesized in the $\mathrm{Pb}\left(\mathrm{NO}_{3}\right)_{2}+\mathrm{MAI}$ solution in DMSO and in DMF solvents elaborated with ReactLab ${ }^{\mathrm{TM}}$ EQUILIBRIA. ${ }^{49}$ a Data from Manser et al. ${ }^{36}$.

\begin{tabular}{cccc}
\hline & DMSO & DMF & DMF $^{\mathbf{a}}$ \\
\hline complex formation & $\log \mathbf{K}$ & $\log \mathbf{K}$ & $\log \mathbf{K}$ \\
\hline $\mathbf{P b}^{2+}+\mathbf{I}^{-} \rightarrow$ PbI $^{+}$ & $3.877 \pm 0.095$ & $3.443 \pm 0.044$ & $/$ \\
$\mathbf{P b I}^{+}+\mathbf{I}^{-} \rightarrow$ PbI $_{2}$ & $3.140 \pm 0.017$ & $2.228 \pm 0.076$ & $/$ \\
$\mathbf{P b I}_{2}+\mathbf{I}^{-} \rightarrow$ PbI$^{-}$ & $0.988 \pm 0.045$ & $2.050 \pm 0.071$ & 1.732 \\
$\mathbf{P b I}^{-}+\mathbf{I}^{-} \rightarrow$ PbI $_{4}{ }^{2-}$ & $0.719 \pm 0.052$ & $/$ & 0.778 \\
\hline
\end{tabular}

The UV-Vis spectrum of a $\mathrm{PbI}_{2}$ solution in DMF (Figure 1b) shows markedly different features. The pristine solution spectrum shows two peaks, at 275 and $323 \mathrm{~nm}$, which are possibly related to solvated $\mathrm{PbI}^{+}$or $\mathrm{PbI}_{2}$ species or a combination of the two. Upon MAI addition, besides an intensity raising of the aforementioned bands, two new peaks with lower intensity emerge up to the visible region, specifically at 370 and $423 \mathrm{~nm}$, pointing at the formation of other iodoplumbate complexes, enriched with iodine, such as $\mathrm{PbI}_{3}{ }^{-}$or $\mathrm{PbI}_{4}{ }^{2-}$. This is in agreement with Manser et al. ${ }^{36}$.

$\mathrm{PbI}_{2}$ was not completely dissolved in GBL and ACN solvents; these solutions remained opalescent indicative of aggregation and other related phenomena, so that the UV-Vis spectra could not be registered in a reproducible way. This did not allow to carry out a comparable investigation of $\mathrm{PbI}_{2}$ in GBL and ACN as was done for DMSO and DMF. To bypass this problem, we directly considered the UV-Vis spectra of $\mathrm{PbI}_{2}+\mathrm{MAI}$ solutions in a 1:5 ratio, that resulted completely dissolved due to the formation of the soluble $\mathrm{PbI}_{3}{ }^{-}$and $\mathrm{PbI}_{4}{ }^{2-}$ iodoplumbates. The presence of these complexes is highlighted by the typical absorption features registered at 370 and $423 \mathrm{~nm}$, in analogy with the DMF solvent. The further addition of 50, 100, 150 and $200 \mu \mathrm{L}$ of MAI $0.1 \mathrm{M}$ confirms this same trend (see Figures S3 and S4 in SI). ${ }^{36}$ The further addition of 50, 100, 150 and $200 \mu \mathrm{L}$ of MAI 0.1 M confirms this same trend (see Figures S3 and S4 in SI).

Comparing the spectral evolution in different solvents, we can conclude that the employed solvent strongly affects the solution chemistry of the solvated $\mathrm{Pb}^{2+}$ ion and its interaction with added MAI, giving rise to different solvated iodoplumbate complexes with different relative 
composition, of the type $\left[\mathrm{PbI}_{\mathrm{m}} \mathrm{X}_{\mathrm{n}}\right]^{2-\mathrm{m}}$, with $\mathrm{X}=$ =solvent. On the basis of recent works, ${ }^{36,37}$ we assign the peaks at 290/323 and 320/370 nm in DMSO/DMF to the $\mathrm{PbI}_{2}$ and $\mathrm{PbI}_{3}{ }^{-}$species, respectively, as reported in Table 2. In DMF a third iodoplumbate complex, $\mathrm{PbI}_{4}{ }^{2-}$, is present, related to the peak at $423 \mathrm{~nm}$, which apparently is not observed in DMSO. In the same way, the low coordinative GBL and $\mathrm{ACN}$ solvents show the $\mathrm{PbI}_{3}{ }^{-}$and $\mathrm{PbI}_{4}{ }^{2-}$ absorption features respectively at $370 / 423 \mathrm{~nm}$. In the same way, the low coordinative GBL and $\mathrm{ACN}$ solvents show $\mathrm{PbI}_{3}{ }^{-}$and $\mathrm{PbI}_{4}{ }^{2-}$ absorption features respectively at $370 / 423 \mathrm{~nm}$. Due to the fact that MAI was added to the reaction container before the spectra were registered, we cannot unambiguously assign the other absorption peaks to the $\mathrm{Pb}^{2+}$, $\mathrm{PbI}^{+}$and $\mathrm{PbI}_{2}$ case as done for $\mathrm{DMSO} / \mathrm{DMF}$. Comparing our data with previous experimental works, ${ }^{40,57}$ we notice how the UV-vis spectra are shifted to lower wavelengths when more coordinative solvents are employed.

Table 2. Absorption maxima (nm) of experimental $\mathrm{UV}-\mathrm{Vis}$ spectra of $\mathrm{Pb}\left(\mathrm{NO}_{3}\right)_{2}+\mathrm{MAI}$ in DMSO and $\mathrm{PbI}_{2}+\mathrm{MAI}$ in DMF, GBL and ACN solutions.

\begin{tabular}{lcccc}
\hline & DMSO & DMF & GBL & ACN \\
\hline $\mathbf{P b}^{2+}$ & 257 & $/$ & $/$ & $/$ \\
$\mathbf{P b I}^{+}$ & 287 & $/$ & $/$ & $/$ \\
$\mathbf{P b I}_{2}$ & 290 & 323 & $/$ & $/$ \\
$\mathbf{P b I}_{3}{ }^{-}$ & 320 & 370 & 370 & 370 \\
$\mathbf{P b I}_{4}{ }^{2-}$ & $/$ & 423 & 423 & 423 \\
\hline
\end{tabular}

The strong influence of the solvent on the optical properties of the $\mathrm{Pb}^{2+}$ complexes can be attributed to several factors, such as an intrinsic solvent effect (solvatochromism), a change in the number of coordinating solvent molecules for a given iodide complex, the different ability of the solvents to dissociate $\mathrm{PbI}_{2}{ }^{58}$ or a combination thereof. The complexity of the iodoplumbate systems and of the involved equilibria pushed us to resort to the use of DFT calculations for the determination of the most thermodynamically stable iodoplumbates in various solvent solutions and of their optical 
properties: besides DMSO and DMF, we explored also the complexes with GBL and ACN for a wider understanding of the solvent effect.
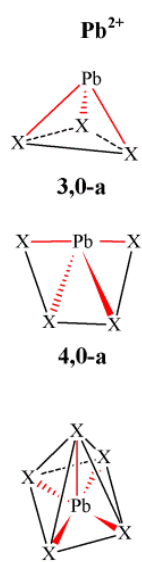

5,0-a

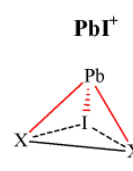

3,1-a
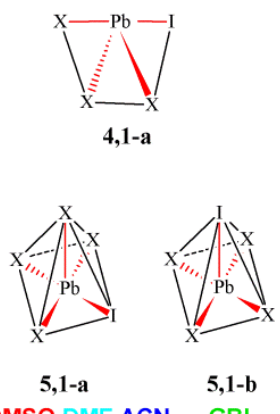

DMSO,DMF,ACN GBL

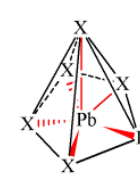

6,1-a DMSO,GBL

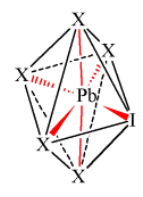

6,1-b DMF,ACN
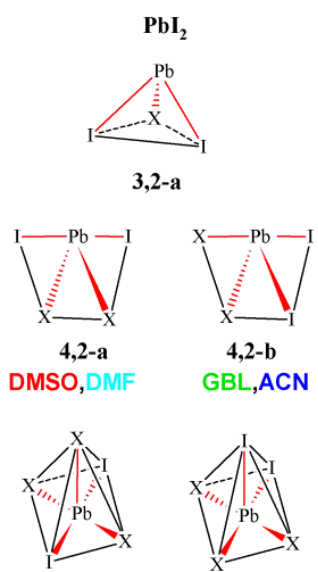

5,2-b

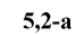

DMSO,DMF,GBL ACN

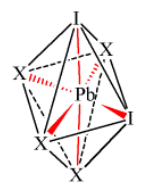

$6,2-\mathrm{a}$ DMSO,DMF

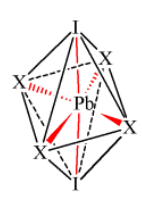

6,2-b GBL,ACN

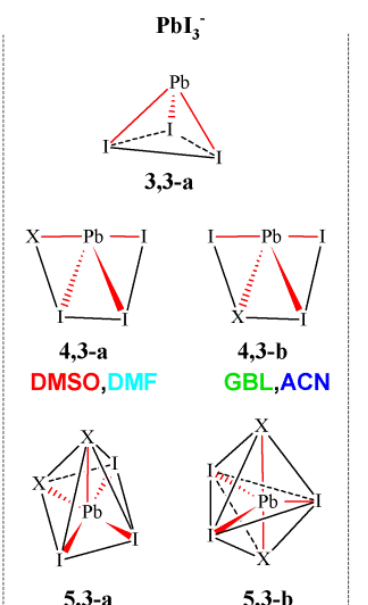

DMSO,DMF GBL,ACN

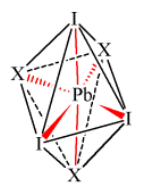

6,3-a DMSO,GBL,ACN

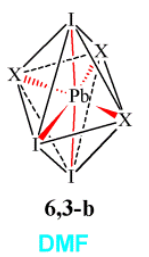

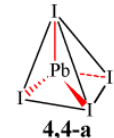

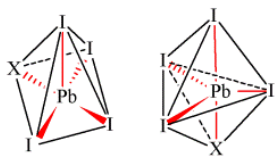

5,4-a $\quad 5,4-b$

DMSO,DMF,GBL ACN

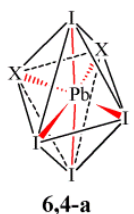

Scheme 1. $\left[\mathrm{PbI}_{\mathrm{m}} \mathrm{X}_{\mathrm{n}}\right]^{2-\mathrm{m}}(\mathrm{X}=$ solvent $)$ most stable coordination, each row referring to a selected coordination number. Each structure is labelled as $\mathbf{c n}, \mathbf{m}-\mathbf{a} / \mathbf{b}$, where $\mathbf{c n}$ is the coordination number, $\mathbf{m}$ counts the iodine atoms and $\mathbf{a} / \mathbf{b}$ refers to different configurations.

Because of the marked effect of the solvent on the iodoplumbates optical properties, we first consider the coordination complexes of the bare $\mathrm{Pb}^{2+}$ ion with the DMSO solvent molecules and we benchmarked the employed computational strategy by comparison with the experimental spectrum of the $\mathrm{Pb}\left(\mathrm{NO}_{3}\right)_{2}$ salt in DMSO. Specifically, we considered $\left[\mathrm{PbX}_{\mathrm{n}}\right]^{2+}$ complexes with $\mathrm{n}$ varying between 3 and 6 . Two distinct structural categories of coordination geometries for the $\mathrm{Pb}^{2+}$ ion can be envisaged: holodirected, where the ligand bonded atoms are directed throughout the surface of an encompassing globe, and hemidirected, where the ligand bonded atoms are directed throughout a limited part of the globe, so that there is an identifiable void (or gap) in the distribution of bonds to the ligands, see Scheme 1. We hereafter classify the investigated structures in terms of the overall 
coordination number, number of iodide ligands, and coordination type. On overall, we investigated eight initial coordination geometries for the $[\mathrm{PbX}]^{2+}$ complexes, specifically hemidirected structures $\mathbf{3 , 0 - a} ; \mathbf{4 , 0 - a} ; \mathbf{5 , 0 - a} ; \mathbf{6 , 0 - a}$ in Scheme $S 1$ and holodirected structures $\mathbf{3 , 0 - b} ; \mathbf{4 , 0 - b} ; \mathbf{5 , 0 - b}$; 6,0-b in Scheme S2. Among these, we report in Figure 2a the energetically favored structures (see also Scheme 1). In agreement with the results from crystallographic data and ab initio calculations, ${ }^{59}$ we found that $\mathrm{Pb}^{2+}$ complexes prefer a hemidirected configuration for low $\mathrm{cn}$, up to 3-5. For the $\mathrm{cn}=6$ case, i.e. for the $\left[\mathrm{PbX}_{6}\right]^{2+}$ complex, both the hemidirected and holodirected coordination gave rise to stable structures, the former being favored by $0.17 \mathrm{eV}$. 
a)
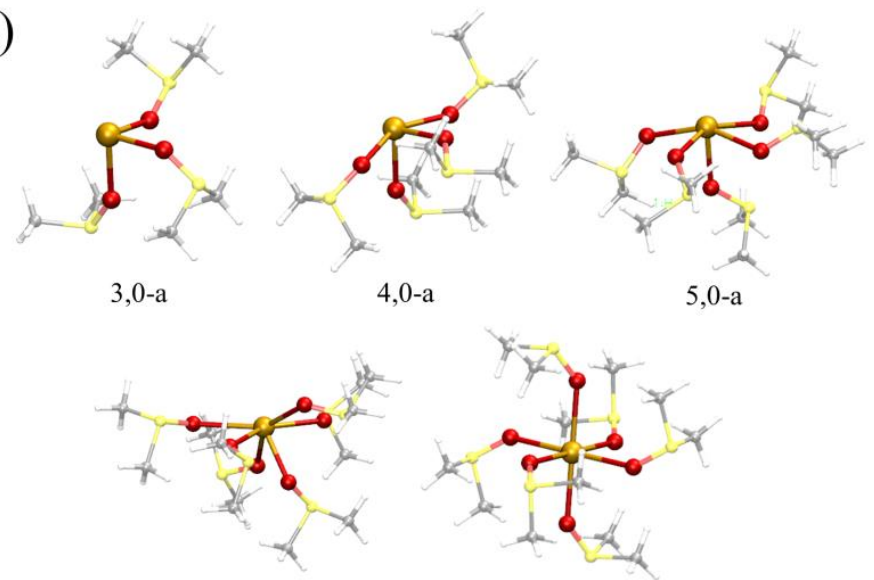

$6,0-\mathrm{a}$

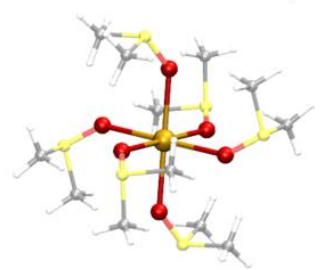

6,0-b

b)

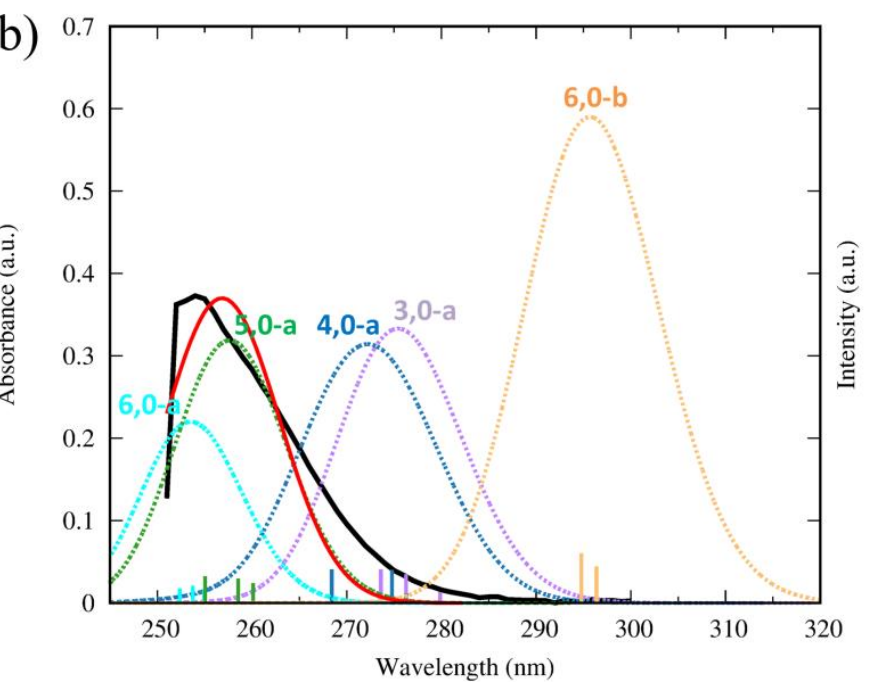

Figure 2. a) Optimized geometrical structures for the $[\mathrm{PbX}]^{2+}(\mathrm{n}=3-6, \mathrm{X}=\mathrm{DMSO})$ complexes; b) their TD-DFT computed spectra (6 lowest in energy excited states) (colored dashed lines, intensity vs wavelength) compared to experimental spectrum of $\mathrm{Pb}\left(\mathrm{NO}_{3}\right)_{2} 0.1 \mathrm{mM}$ in DMSO (solid black line, absorbance vs wavelength). The solid red line refers to a fit of $\mathbf{5 , 0 - a}$ and $\mathbf{6 , 0}-\mathbf{a}$ spectra to the experimental one.

For the more stable $\left[\mathrm{PbX}_{\mathrm{n}}\right]^{2+}(\mathrm{X}=\mathrm{DMSO})$ complexes of Figure 2a, we simulated the UV-Vis absorption spectra by TD-DFT employing SOC, by computing several excitation energies and oscillator strengths. The results are reported in Figure $2 \mathrm{~b}$, together with the experimental $\mathrm{Pb}\left(\mathrm{NO}_{3}\right)_{2}$ spectrum in DMSO for a direct comparison. Remarkably, the number of coordinated DMSO molecules strongly affects the absorption maxima energy. In particular, $\mathbf{3 , 0 - a}$ shows an absorption 
maximum at $275 \mathrm{~nm}$, that slightly shifts to $272 \mathrm{~nm}$ for $\mathbf{4 , 0 - a}$ and shifts further to 254 for $\mathbf{5 , 0 - a}$. For a coordination number equal to 6 a strong difference is found for hemidirected and holodirected $\left[\mathrm{PbX}_{6}\right]^{2+}$ complexes $\mathbf{6 , 0 - a}$ and $\mathbf{6 , 0 - b}$, characterized respectively by calculated absorption maxima at 258 and $296 \mathrm{~nm}$. Comparing the calculated spectra to the experimental data showing an absorption maximum at $257 \mathrm{~nm}$, we conclude that the solution composition is dominated by $\mathbf{6 , 0} \mathbf{0}$-a, with a possible contribution from $\mathbf{5 , 0 - a}$, thus suggesting that the $\mathrm{Pb}^{2+}$ ion preferentially coordinates 5-6 DMSO solvent molecules, with coordination number equal to 6 dominated by the hemidirected coordination. A fit of the experimental spectrum with the computed $\mathbf{6 , 0 - a}$ and $\mathbf{5 - 0 - a}$ [see Figure 2 b)] was carried out considering a linear combination of the two gaussian functions that describe our theoretical spectra, as reported here:

$c_{1} *\left(y_{0,1}+A_{1} * \frac{\sqrt{2 / \pi}}{w_{1}} * e^{\left(\frac{-2 *\left(x-x_{c, 1}\right)}{w_{1}}\right)^{2}}\right)+c_{2} *\left(y_{0,2}+A_{2} * \frac{\sqrt{2 / \pi}}{w_{2}} * e^{\left(\frac{-2 *\left(x-x_{c, 2}\right)}{w_{2}}\right)^{2}}\right)$

where the parameters with the subscript 1 refer to the $\mathbf{5 , 0 - a}$ spectrum while those with the subscript 2 are for the $\mathbf{6 , 0 - a}$. The optimization was performed only on the linear combination coefficients $c_{1}$ and $c_{2}$ through an iterative algorithm (scaled Levenberg-Marquardt), that resulted in absolute values of 0.4054 and 0.9382 respectively for $c_{1}$ and $c_{2}$, thus suggesting the higher contribution of the $\mathbf{6 , 0} \mathbf{0}$ spectrum to the experimental one.

Our finding is in agreement with the work of Persson et al., ${ }^{60}$ showing the hemidirected $\left[\mathrm{PbX}_{6}\right]^{2+}$ complex to be the main species found in a DMSO solution of $\mathrm{Pb}\left(\mathrm{NO}_{3}\right)_{2}$, thus confirming the quality of the employed theoretical setup and making us confident on the subsequent assignments.

As outlined above, by adding increasing amounts of MAI to the $\mathrm{Pb}^{2+}$ salt solution, the formation of various iodoplumbate complexes, $\left[\mathrm{PbI}_{\mathrm{m}} \mathrm{X}_{\mathrm{n}}\right]^{2-\mathrm{m}}$ with $\mathrm{m}=1-4$ is surmised. Our results on the $[\mathrm{PbX}]^{2+}(\mathrm{X}=\mathrm{DMSO})$ complexes highlight the key role of the coordinating solvent molecules on the optical properties of the ensuing complexes. Accordingly, we carried out geometry optimizations of the hypothesized iodoplumbate complexes including in the coordination sphere an 
increasing number of solvent molecules. It is worth noting that the presence of two different ligands in the $\mathrm{Pb}^{2+}$ coordination sphere, namely the halogen $\mathrm{I}$ and the solvent $\mathrm{X}$, increases the possible coordination geometries of the solvated iodoplumbate complexes. On overall, we attempted 29 and 24 distinct hemidirected and holodirected configurations, respectively (see Schemes S1 and S2 in the SI); in Scheme 1 the most energetically stable structures are drawn. Notably, the stability of the various complexes depends on the nature of the solvent, see Scheme 1. Shimoni-Livny et al. ${ }^{59}$ carried out an extended analysis on the coordination geometry of divalent lead compounds by crystallographic data and ab initio calculations, concluding that $\mathrm{Pb}^{2+}$ complexes prefer hemidirected and holodirected configuration for low and high coordination number, respectively. For intermediate coordination number values, both holodirected and hemidirected coordinations are found, but the holodirected geometry tends to prevail for iodide ligands. Our results are substantially in agreement with these findings, even if some differences are found, in dependence of the solvent employed in the coordination sphere. The relative formation energies for different complexes are reported against the number of solvent molecules in Figure 3. 


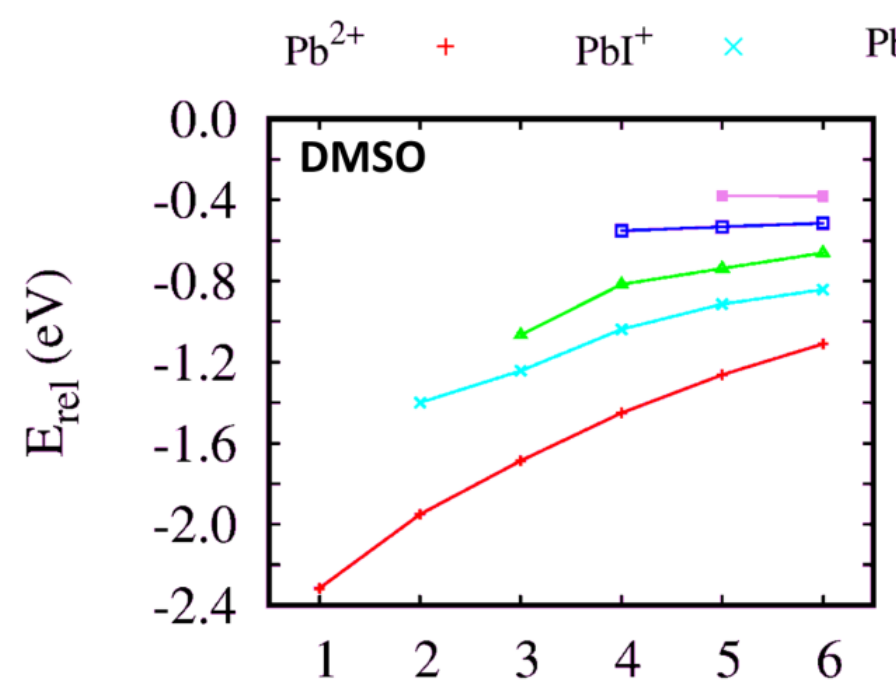

$\mathrm{PbI}_{2} \Delta \mathrm{PbI}_{3}^{-} \quad \square \quad \mathrm{PbI}_{4}{ }^{-}$
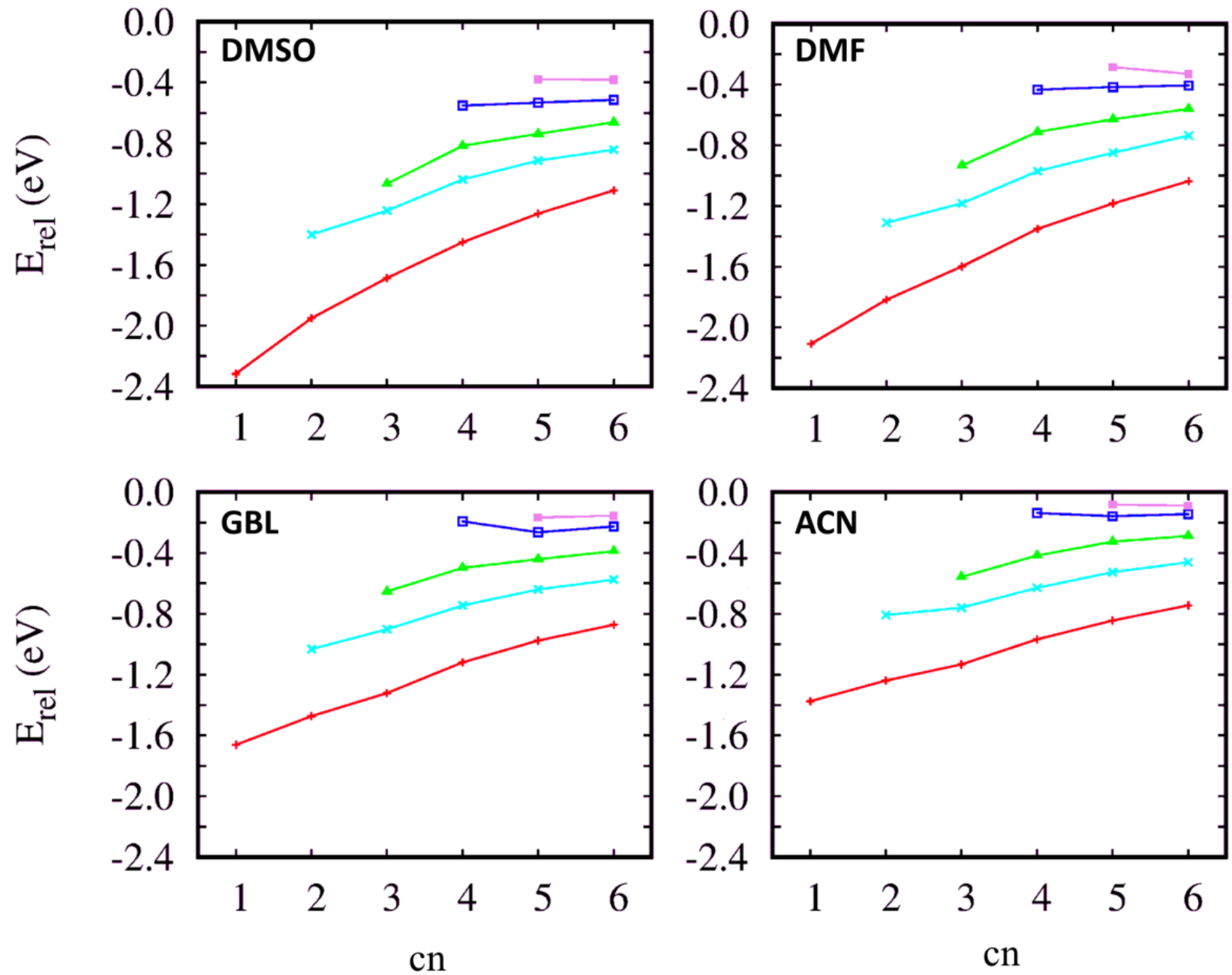

Figure 3. Relative formation energies $\left(E_{r e l}\right.$, in $\left.\mathrm{eV}\right)$ of solvated iodoplumbates $\left[\mathrm{PbI}_{\mathrm{m}} \mathrm{X}_{\mathrm{n}}\right]^{2-\mathrm{m}}$ vs the total coordination number $(\mathrm{cn})$, for various employed solvents.

As it can be noticed, DMSO shows the highest stabilization energy upon coordination for each iodoplumbate complex, followed by DMF, GBL and ACN. The computed values for the iodoplumbate energy solvation can be related to the solvent coordinative power, since higher energy stabilization values correspond to higher coordinative powers. On the basis of the energy values in Figure 3, the following trend for the energy solvation can be envisaged: DMSO > DMF > GBL > ACN, that is in fairly good agreement with the well-known coordinative solvent power. ${ }^{58,61-64}$ Interestingly, the experimental solubility of $\mathrm{PbI}_{2}$ in the various solvents (see Table $\mathrm{S} 4$ ) follows the 
same trend, as also reported by Stevenson et al. ${ }^{65}$ in line with the expected relation between solvent coordination ability and $\mathrm{Pb}^{2+}$ solubility and with the donor number of the solvents. ${ }^{57,66}$

To correlate the obtained theoretical and experimental findings, we carried out the simulation of the absorption spectra for the $\left[\mathrm{PbI}_{\mathrm{m}} \mathrm{X}_{\mathrm{n}}\right]^{2-\mathrm{m}}$ iodoplumbate complexes $(\mathrm{X}=\mathrm{DMSO}$ and DMF) that were computed to be more stable in energy, as per Scheme 1. In particular, in Figures 4 and 5 we report the absorption spectra of selected $\left[\mathrm{PbI}_{\mathrm{m}} \mathrm{X}_{\mathrm{n}}\right]^{2-\mathrm{m}}$ iodoplumbate complexes, that most resemble the experimental spectra of lead salt solutions with the addition of MAI, respectively for DMSO and DMF. Other simulated absorption spectra are shown in the SI. 


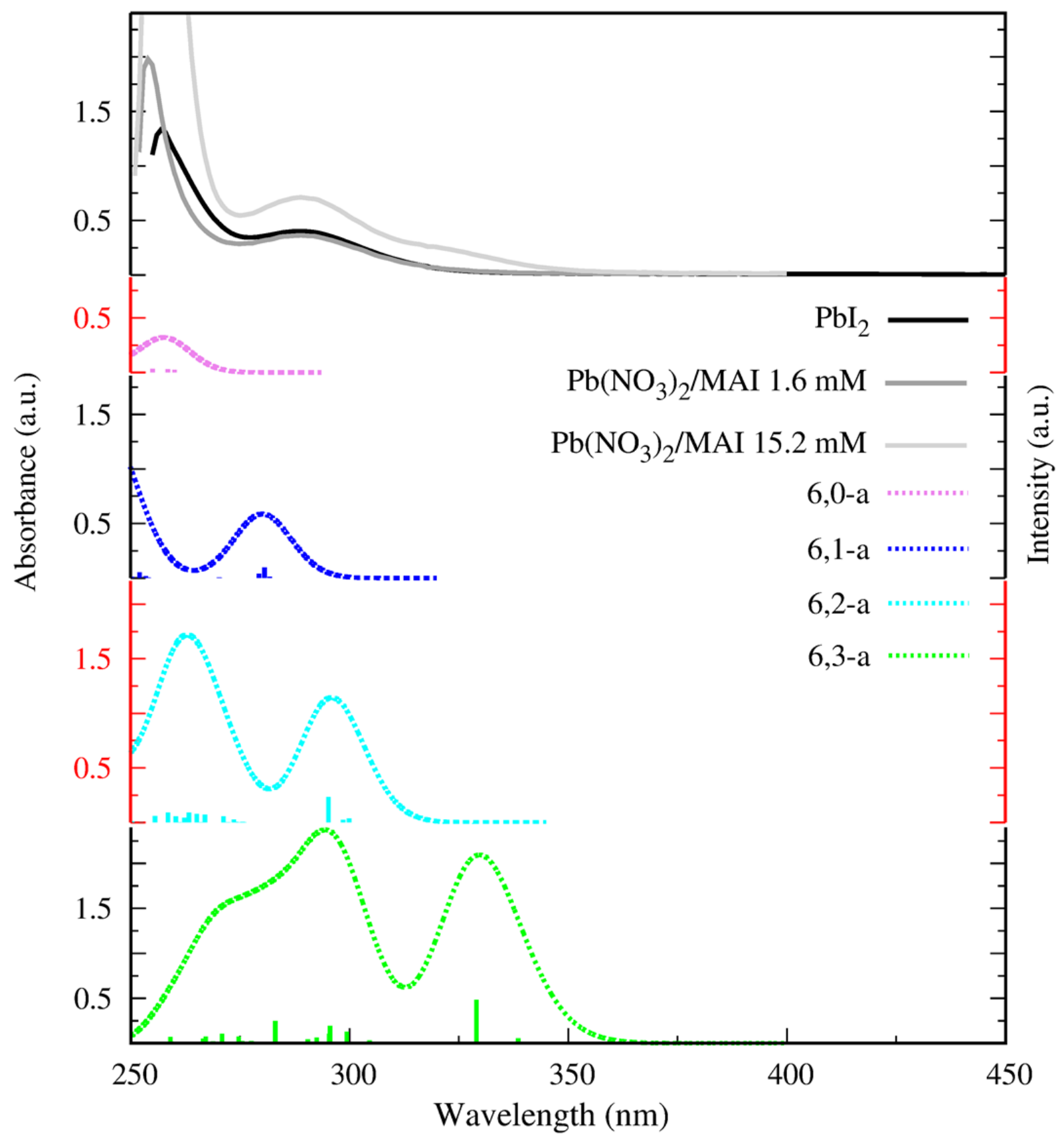

Figure 4. Comparison between computed (dotted lines) absorption spectra for selected $\left[\mathrm{PbI}_{\mathrm{m}} \mathrm{X}_{\mathrm{n}}\right]^{2-\mathrm{m}}$ iodoplumbate complexes and experimental UV-Vis (solid lines) absorption spectra of $\mathrm{PbI}_{2}$ solution without addition of MAI and $\mathrm{Pb}\left(\mathrm{NO}_{3}\right)_{2}$ solution with the addition of MAI 1.6 / 15.2 mM in DMSO. 


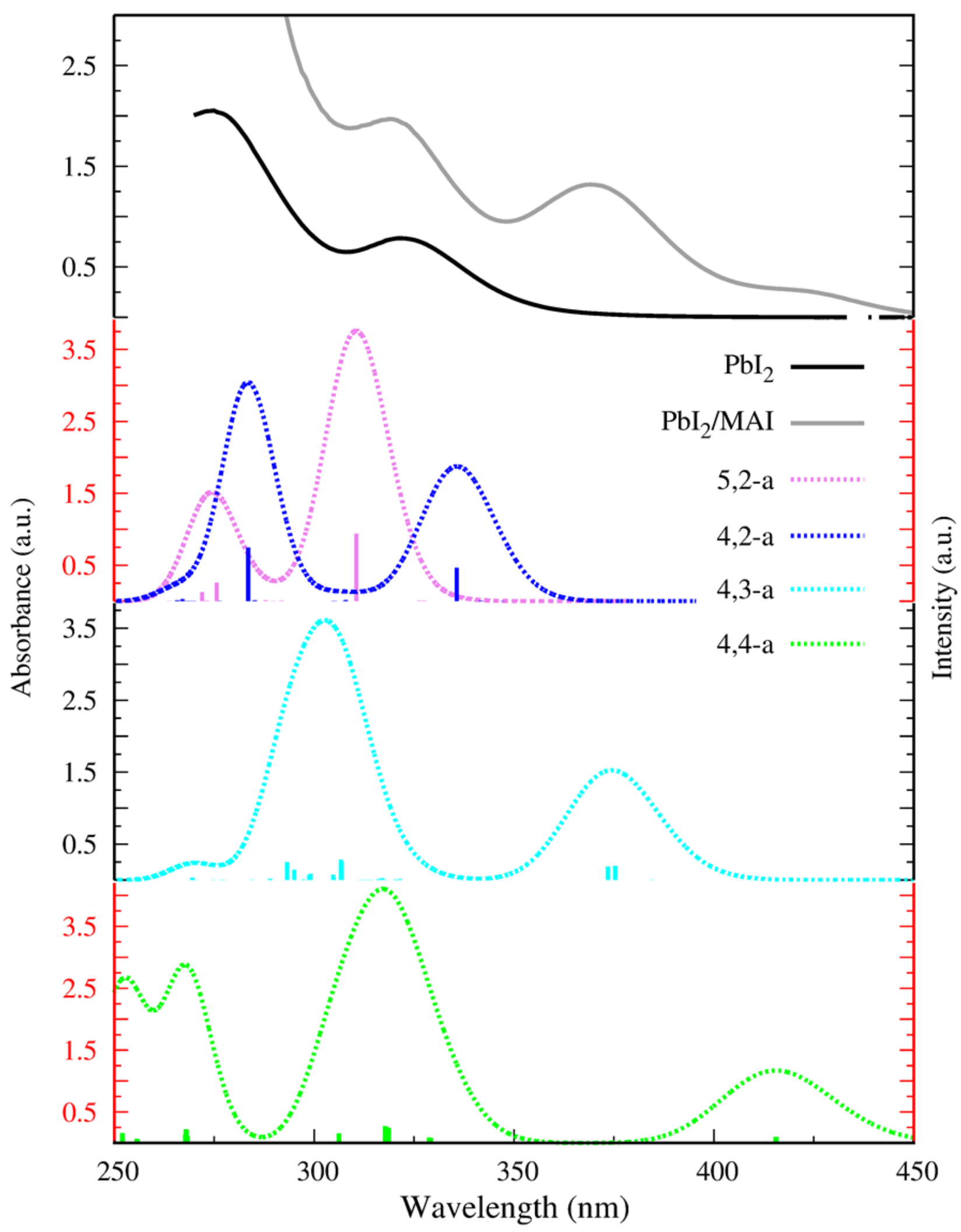

Figure 5. Comparison between computed (dotted lines) absorption spectra for selected $\left[\mathrm{PbI}_{\mathrm{m}} \mathrm{X}_{\mathrm{n}}\right]^{2-\mathrm{m}}$ iodoplumbate complexes and experimental UV-Vis (solid lines) absorption spectra of $\mathrm{PbI}_{2}$ solution without and with the addition of MAI $24.0 \mathrm{mM}$ in DMF. 
As already discussed, we can see that the experimental spectra of lead solutions show two absorption features, at 257/290 $\mathrm{nm}$ in DMSO (Figure 4) and 275/323 $\mathrm{nm}$ in DMF (Figure 5). Interestingly, the $\mathrm{PbI}_{2} \mathrm{X}_{4}$ 6,2-a spectrum, see structure in Figure 6, well describes the experimental spectrum of lead solutions in DMSO, with calculated absorption maxima at 264/295 nm against experimental values of 257/290 $\mathrm{nm}$ (see Figure 4). In DMF the spectrum that more closely matches the experimental one is that of $\mathrm{PbI}_{2} \mathrm{X}_{3}$ 5,2-a, see structure in Figure 6, with absorption maxima of $275 / 311 \mathrm{~nm}$ against $275 / 323 \mathrm{~nm}$ experimental values, though the spectrum of $\mathrm{PbI}_{2} \mathrm{X}_{2} \mathbf{4 , 2}-\mathbf{a}$ is also quite close to the experimental one (see Figure 5). Remarkably, a coordination number equal to 6 was found for other $\mathrm{Pb}$ salts in $\mathrm{DMF},{ }^{60}$ thus suggesting that the total coordination number could be could be significantly dependent on the ligand coordination sphere.

A comparison of pseudo-octahedral structures with increasing number of iodide ligands in DMSO, namely $\left[\mathrm{PbX}_{6}\right]^{2+} \mathbf{6 , 0 - a},\left[\mathrm{PbIX}_{5}\right]^{+} \mathbf{6 , 1 - a}, \mathrm{PbI}_{2} \mathrm{X}_{4} \mathbf{6 , 2 - a}$ and $\left[\mathrm{PbI}_{3} \mathrm{X}_{3}\right]^{-} \mathbf{6 , 3 - a}$, is reported in Figure 6. As discussed above and reported in Figure 4, the $\left[\mathrm{PbX}_{6}\right]^{2+} \mathbf{6 , 0 - a}$ complex shows a peak centered at $257 \mathrm{~nm}$. As expected, when considering the excitations for the other iodoplumbate complexes, several absorption bands appear at shorter wavelengths. In particular, for the $\left[\mathrm{PbIX}_{5}\right]^{+}$ 6,1-a complex, we computed a strong absorption band centered at $240 \mathrm{~nm}$, together with a peak at $280 \mathrm{~nm}$. As reported before, also for the $\mathrm{PbI}_{2} \mathrm{X}_{4}$ 6,2-a complex we computed two peaks, at 264 and $295 \mathrm{~nm}$. Remarkably, the absorption spectrum of the $\left[\mathrm{PbI}_{3} \mathrm{X}_{3}\right]^{-} \mathbf{6 , 3 - a}$ complex strongly differs from that of the other species, since it shows a peak at $295 \mathrm{~nm}$, with a shoulder at $270 \mathrm{~nm}$, and another at $329 \mathrm{~nm}$, with very high intensity. This last feature cannot be seen from the experimental spectrum of a $0.24 \mathrm{mM} \mathrm{PbI}_{2}$ solution, but appears when a relatively high quantity of MAI is added to $\mathrm{Pb}\left(\mathrm{NO}_{3}\right)_{2} \quad 0.1 \mathrm{mM}$ (see Figure 1). According to the present results, we can surmise that the experimental peak centered at $290 \mathrm{~nm}$ (see Figure 1) can be related to the $\left[\mathrm{PbI}_{3} \mathrm{X}_{3}\right]^{-}, \mathrm{PbI}_{2} \mathrm{X}_{4}$ and $[\mathrm{PbIX} 5]^{+}$complexes, while the experimental peak centered at $320 \mathrm{~nm}$ can be related exclusively to the $\left[\mathrm{PbI}_{3} \mathrm{X}_{3}\right]^{-}$complex. 
For the iodoplumbate complexes in DMF solvent with the addition of MAI, we selected

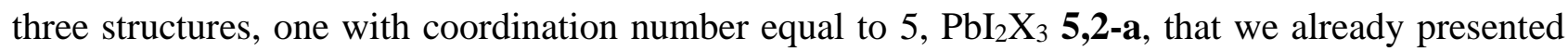
earlier for the excellent agreement with the experimental bands, and two with coordination number equal to 4, $\left[\mathrm{PbI}_{3} \mathrm{X}\right]^{-}$4,3-a and $\left[\mathrm{PbI}_{4}\right]^{2-}$ 4,4-a without coordinating DMF molecules, see Figure 6. For the $\left[\mathrm{PbI}_{3} \mathrm{X}\right]^{-}$4,3-a complex, we computed a band with low intensity at $270 \mathrm{~nm}$ and two other bands centered at 302 and $375 \mathrm{~nm}$. Finally, the $\left[\mathrm{PbI}_{4}\right]^{2-} \mathbf{4 , 4 - a}$ shows two outdistanced peaks at 317 and $416 \mathrm{~nm}$. On the basis of the experimental results reported in Figure 1, we unambiguously assign the peak at $423 \mathrm{~nm}$ to the $\mathrm{PbI}_{4}{ }^{2-}$ species, while the peak at $370 \mathrm{~nm}$ could result from the absorption of various species, such as $\left[\mathrm{PbI}_{4}\right]^{2-},\left[\mathrm{PbI}_{3} \mathrm{X}\right]^{-}$and $\mathrm{PbI}_{2} \mathrm{X}_{3}$.

A complete overview of the presented experimental and theoretical data is reported in Table 3.

Table 3. Comparison of experimental (Exp) and computed (Th) absorption maxima (nm) of the investigated $\left[\mathrm{PbI}_{\mathrm{m}} \mathrm{X}_{\mathrm{n}}\right]^{2-\mathrm{m}}$ structures in DMSO and DMF solvents.

\begin{tabular}{|c|c|c|c|c|c|c|}
\hline \multirow[b]{2}{*}{$\mathbf{P b I} \mathbf{m}^{2-m}$} & \multicolumn{3}{|c|}{ DMSO } & \multicolumn{3}{|c|}{ DMF } \\
\hline & Exp & Th & & $\operatorname{Exp}$ & Th & \\
\hline $\mathbf{P b}^{2+}$ & 257 & $\begin{array}{l}275 \\
272 \\
254 \\
258 \\
296\end{array}$ & $\begin{array}{l}(3,0-\mathbf{a}) \\
(4,0-\mathbf{a}) \\
(\mathbf{5 , 0}-\mathbf{a}) \\
(\mathbf{6 , 0 - a}) \\
(\mathbf{6 , 0 - b})\end{array}$ & I & I & I \\
\hline $\mathbf{P b I}^{+}$ & $257 / 287$ & $240 / 280$ & $(6,1-a)$ & I & I & I \\
\hline $\mathbf{P b I}_{2}$ & 290 & $\begin{array}{c}254 / 267 / 294 / 317 / 34 \\
7 \\
274 / 340 \\
311 \\
264 / 295\end{array}$ & $\begin{array}{l}(3,2-\mathbf{a}) \\
(4,2-\mathbf{a}) \\
(5,2-\mathbf{a}) \\
(6,2-\mathbf{a})\end{array}$ & $275 / 323$ & $\begin{array}{c}292 / 316 / 345 \\
284 / 336 \\
275 / 311 \\
267 / 292\end{array}$ & $\begin{array}{l}(3,2-\mathbf{a}) \\
(4,2-\mathbf{a}) \\
(5,2-\mathbf{a}) \\
(6,2-\mathbf{a})\end{array}$ \\
\hline $\mathrm{PbI}_{3}^{-}$ & 320 & 270/295/329 & $(6,3-a)$ & 370 & $270 / 302 / 375$ & $(4,3-a)$ \\
\hline
\end{tabular}




\begin{tabular}{l|l|l|ll}
$\mathbf{P b I}_{4}^{2-}$ & $/$ & $/$ & 423 & $317 / 416 \quad(\mathbf{4 , 4 - a})$
\end{tabular}

\section{DMSO}

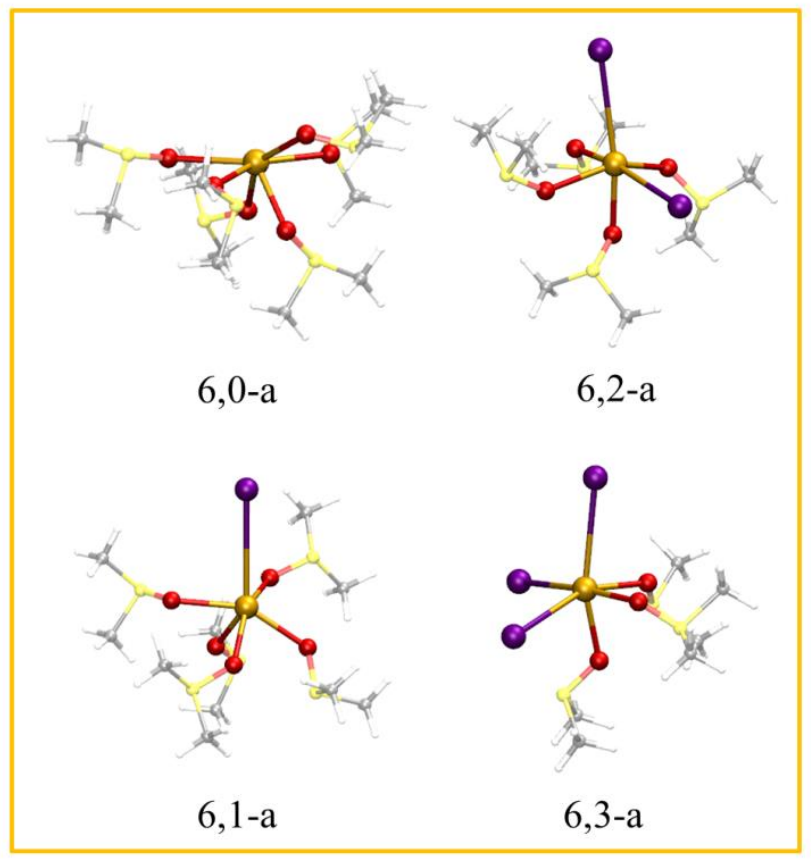

DMF

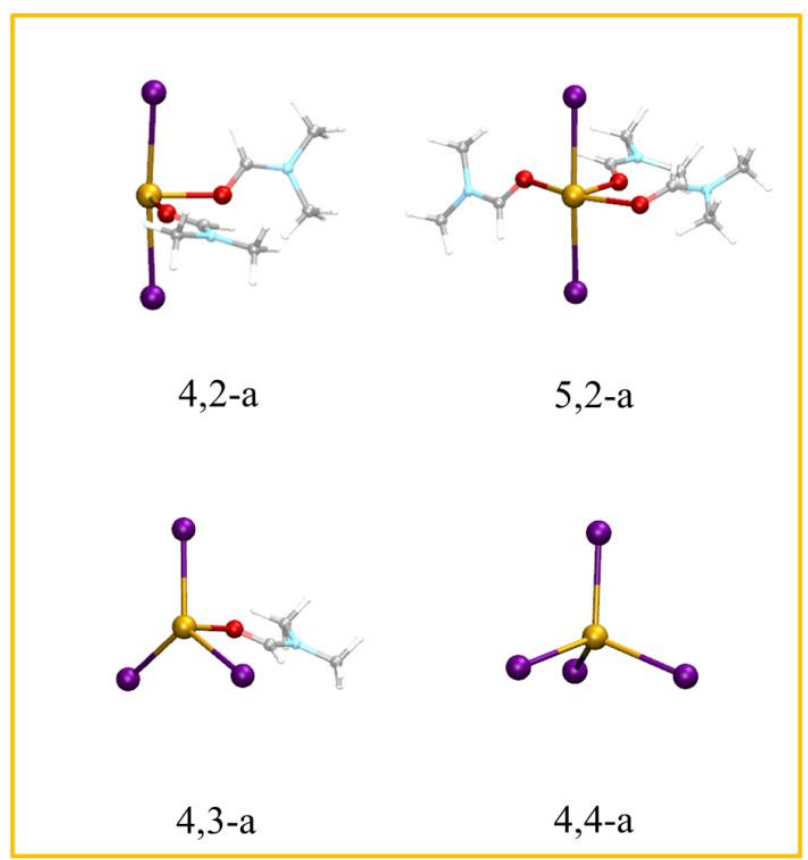

Figure 6. Optimized geometries for selected $\left[\mathrm{PbI}_{\mathrm{m}} \mathrm{X}_{\mathrm{n}}\right]^{2-\mathrm{m}}$ iodoplumbate complexes in DMSO (left) and DMF (right) solvents.

Our results show that the iodoplumbate species that are most likely to be present in the DMSO solution environment have a higher coordination number than those in DMF, with the consequence that in DMSO iodoplumbates with a lower number of iodide ligands are preferred. In other words, the stronger solvent coordination partially displaces the fairly weak iodide ligands, so that lower iodide complexes are favored in DMSO against DMF. This could be addressed to the higher coordinating ability of DMSO with respect to DMF, ${ }^{54}$ and it likely can be extrapolated to other solvents.

The different coordination number and composition of solvated iodoplumbates obtained in different solvents may have important consequences for the kinetics of perovskite formation. As a matter of fact, the stronger $\mathrm{Pb}$-solvent interaction in DMSO will likely slow down the 
crystallization process upon evaporating the solvent, since it will be more difficult to abstract solvent molecules from the precursors. In this case, the lower tendency to form species with higher number of iodide ligands may at the same time give rise to a less defective structure, which may minimize the incorporation of extra iodine in the lattice in the form of e.g. interstitial iodine. In DMF the preferred species have low coordination number and a comparatively higher iodide content, thus upon the fast solvent evaporation, some of the extra iodide originated by e.g. $\mathrm{PbI}_{4}^{2-}$ species, may be transferred to the perovskite lattice with possible detrimental consequences on the material optoelectronic quality. At the same time, the weaker $\mathrm{Pb}$-solvent interaction will likely speed up the formation of crystal grains grown under non-equilibrium conditions, possibly leading to a more disordered material.

\section{Conclusions}

Uncovering the mechanisms that lead to the formation of the perovskite polycrystalline thin films is crucial in order to understand how these changes reflect in the final perovskite properties and so to be able to improve these properties tuning the solution chemistry. In the present work we have identified the composition of the solvated iodoplumbate complexes involved in a common perovskite precursors DMSO/DMF solution by means of a combined experimental and theoretical strategy. Experimental spectra gave us a view of the species in solution, that were analyzed by fitting software for the evaluation of the spectral shapes and equilibrium constants of the different species. Upon addition of MAI to the lead solution, several absorption bands appear at lower wavelength. The specific molecular interactions between the iodoplumbate complexes, $\left[\mathrm{PbI} \mathrm{I}_{\mathrm{m}}\right]^{2-\mathrm{m}}$, and the solvent molecules, $\mathrm{X}$, upon addition of MAI were analyzed by identifying the most thermodynamically stable structures in various solvent solutions and characterizing their optical properties trough DFT and TD-DFT calculations. The theoretical strategy was first benchmarked comparing simulated spectra of selected optimized complexes with the experimental UV-Vis spectrum of a $\mathrm{Pb}\left(\mathrm{NO}_{3}\right)_{2}$ in DMSO solution. Then, the formation energies of the simulated 
complexes and the comparison between experimental and theoretical absorption spectra were used to shed light on the coordinative power of various solvents to the iodoplumbates species and their specific interactions, giving us the possibility to predict the number of iodide ions and of solvent molecules coordinated to the $\mathrm{Pb}^{2+}$ center. In this way, we have found that iodoplumbate-DMSO complexes have, on average, a higher coordination number and a lower iodide ligand number with respect to the iodoplumbate-DMF ones. Specifically, the experimental spectra of lead solutions in DMSO are adequately describe by the spectra computed for the $\mathrm{PbI}_{2} \mathrm{X}_{4} \mathbf{6 , 2 - \mathbf { a }},\left[\mathrm{PbI}_{3} \mathrm{X}_{3}\right]^{-} \mathbf{6 , 3 - a}$ and $\left[\mathrm{PbIX}_{5}\right]^{+}$6,1-a structures, while in DMF solvent the spectra that more closely match with the experimental ones are those related to $\mathrm{PbI}_{2} \mathrm{X}_{3}$ 5,2-a, $\mathrm{PbI}_{2} \mathrm{X}_{2}$ 4,2-a, $\left[\mathrm{PbI}_{3} \mathrm{X}\right]^{-} \mathbf{4 , 3 - a}$ and $\left[\mathrm{PbI}_{4}\right]^{2-}$ 4,4-a structures. Our combined computational and experimental analysis points out the critical role of the nature of the solvent in affecting the perovskite precursor solution, with possible important consequences on the ensuing material optoelectronic quality. As a general conclusion, we illustrate how weaker coordinating solvents give preferentially rise to iodoplumbates with higher iodide content and lower solvent coordinated molecules, with a likely impact on the kinetics of perovskite formation.

Supporting Information Optimized structures and experimental and simulated absorption spectra for the investigated iodoplumbate complexes.

\section{Acknowledgements}

The authors acknowledge support from the Italian "Ministero per l'Università e la Ricerca Scientifica e Tecnologica", MIUR (Rome, Italy) and the University of Perugia, under the "Dipartimenti di Eccellenza 2018-2022" (grant AMIS) and the FRB-2015 programs, from the University of Perugia under the "Fondo Ricerca di Base 2015" program and from the European Union's Horizon 2020 research and innovation programme, under grant agreement No 764047. 


\section{References}

(1) Snaith, H. J. Perovskites: The Emergence of a New Era for Low-Cost, High-Efficiency Solar Cells. J. Phys. Chem. Lett. 2013, 4 (21), 3623-3630. https://doi.org/10.1021/jz4020162.

(2) Green, M. A.; Ho-Baillie, A.; Snaith, H. J. The Emergence of Perovskite Solar Cells. Nat. Photonics 2014, 8 (7), 506-514. https://doi.org/10.1038/nphoton.2014.134.

(3) Photovoltaic Research | NREL https://www.nrel.gov/pv/.

(4) Lin, Q.; Armin, A.; Burn, P. L.; Meredith, P. Organohalide Perovskites for Solar Energy Conversion. Acc. Chem. Res. 2016, 49 (3), 545-553. https://doi.org/10.1021/acs.accounts.5b00483.

(5) Zhao, Y.; Zhu, K. Solution Chemistry Engineering toward High-Efficiency Perovskite Solar Cells. J. Phys. Chem. Lett. 2014, 5 (23), 4175-4186. https://doi.org/10.1021/jz501983v.

(6) Yang, M.; Zhang, T.; Schulz, P.; Li, Z.; Li, G.; Kim, D. H.; Guo, N.; Berry, J. J.; Zhu, K.; Zhao, Y. Facile Fabrication of Large-Grain $\mathrm{CH}_{3} \mathrm{NH}_{3} \mathrm{Pbl}_{3-x} \mathrm{Br}_{x}$ Films for High-Efficiency Solar Cells via $\mathrm{CH}_{3} \mathrm{NH}_{3} \mathrm{Br}$ Selective Ostwald Ripening. Nat. Commun. 2016, 7, 12305. https://doi.org/10.1038/ncomms12305.

(7) Etgar, L.; Gao, P.; Xue, Z.; Peng, Q.; Chandiran, A. K.; Liu, B.; Nazeeruddin, Md. K.; Grätzel, M. Mesoscopic $\mathrm{CH}_{3} \mathrm{NH}_{3} \mathrm{Pbl}_{3} / \mathrm{TiO}_{2}$ Heterojunction Solar Cells. J. Am. Chem. Soc. 2012, 134 (42), 1739617399. https://doi.org/10.1021/ja307789s.

(8) Seo, J.; Park, S.; Kim, Y. C.; Jeon, N. J.; Noh, J. H.; Yoon, S. C.; Seok, S. I. Benefits of Very Thin PCBM and LiF Layers for Solution-Processed p-i-n Perovskite Solar Cells. Energy Environ. Sci. 2014, 7 (8), 2642-2646. https://doi.org/10.1039/C4EE01216J.

(9) Manser, J. S.; Reid, B.; Kamat, P. V. Evolution of Organic-Inorganic Lead Halide Perovskite from SolidState lodoplumbate Complexes. J. Phys. Chem. C 2015, 119 (30), 17065-17073. https://doi.org/10.1021/acs.jpcc.5b05898.

(10) Moore, D. T.; Sai, H.; Tan, K. W.; Smilgies, D.-M.; Zhang, W.; Snaith, H. J.; Wiesner, U.; Estroff, L. A. Crystallization Kinetics of Organic-Inorganic Trihalide Perovskites and the Role of the Lead Anion in Crystal Growth. J. Am. Chem. Soc. 2015, 137 (6), 2350-2358. https://doi.org/10.1021/ja512117e.

(11) Williams, S. T.; Zuo, F.; Chueh, C.-C.; Liao, C.-Y.; Liang, P.-W.; Jen, A. K.-Y. Role of Chloride in the Morphological Evolution of Organo-Lead Halide Perovskite Thin Films. ACS Nano 2014, 8 (10), 10640-10654. https://doi.org/10.1021/nn5041922.

(12) Colella, S.; Mosconi, E.; Fedeli, P.; Listorti, A.; Gazza, F.; Orlandi, F.; Ferro, P.; Besagni, T.; Rizzo, A.; Calestani, G.; et al. MAPbl ${ }_{3-x} \mathrm{Cl}_{x}$ Mixed Halide Perovskite for Hybrid Solar Cells: The Role of Chloride as Dopant on the Transport and Structural Properties. Chem. Mater. 2013, 25 (22), 4613-4618. https://doi.org/10.1021/cm402919x.

(13) Ahn, N.; Son, D.-Y.; Jang, I.-H.; Kang, S. M.; Choi, M.; Park, N.-G. Highly Reproducible Perovskite Solar Cells with Average Efficiency of $18.3 \%$ and Best Efficiency of $19.7 \%$ Fabricated via Lewis Base Adduct of Lead(II) lodide. J. Am. Chem. Soc. 2015, 137 (27), 8696-8699. https://doi.org/10.1021/jacs.5b04930.

(14) Yang, W. S.; Noh, J. H.; Jeon, N. J.; Kim, Y. C.; Ryu, S.; Seo, J.; Seok, S. I. High-Performance Photovoltaic Perovskite Layers Fabricated Through Intramolecular Exchange. Science 2015, 348 (6240), 1234-1237. https://doi.org/10.1126/science.aaa9272.

(15) Guo, Y.; Shoyama, K.; Sato, W.; Matsuo, Y.; Inoue, K.; Harano, K.; Liu, C.; Tanaka, H.; Nakamura, E. Chemical Pathways Connecting Lead(II) lodide and Perovskite via Polymeric Plumbate(II) Fiber. J. Am. Chem. Soc. 2015, 137 (50), 15907-15914. https://doi.org/10.1021/jacs.5b10599.

(16) Yan, K.; Long, M.; Zhang, T.; Wei, Z.; Chen, H.; Yang, S.; Xu, J. Hybrid Halide Perovskite Solar Cell Precursors: Colloidal Chemistry and Coordination Engineering behind Device Processing for High Efficiency. J. Am. Chem. Soc. 2015, 137 (13), 4460-4468. https://doi.org/10.1021/jacs.5b00321.

(17) Zhao, Y.; Zhu, K. CH $\mathrm{CH}_{3} \mathrm{Cl}$-Assisted One-Step Solution Growth of $\mathrm{CH}_{3} \mathrm{NH}_{3} \mathrm{Pbl}_{3}$ : Structure, ChargeCarrier Dynamics, and Photovoltaic Properties of Perovskite Solar Cells. J. Phys. Chem. C 2014, 118 (18), 9412-9418. https://doi.org/10.1021/jp502696w.

(18) McMeekin, D. P.; Wang, Z.; Rehman, W.; Pulvirenti, F.; Patel, J. B.; Noel, N. K.; Johnston, M. B.; Marder, S. R.; Herz, L. M.; Snaith, H. J. Crystallization Kinetics and Morphology Control of 
Formamidinium-Cesium Mixed-Cation Lead Mixed-Halide Perovskite via Tunability of the Colloidal Precursor Solution. Adv. Mater. 2017, 29 (29), 1607039. https://doi.org/10.1002/adma.201607039.

(19) Noel, N. K.; Congiu, M.; Ramadan, A. J.; Fearn, S.; McMeekin, D. P.; Patel, J. B.; Johnston, M. B.; Wenger, B.; Snaith, H. J. Unveiling the Influence of PH on the Crystallization of Hybrid Perovskites, Delivering Low Voltage Loss Photovoltaics. Joule 2017, 1 (2), 328-343. https://doi.org/10.1016/j.joule.2017.09.009.

(20) Ramadan, A. J.; Noel, N. K.; Fearn, S.; Young, N.; Walker, M.; Rochford, L. A.; Snaith, H. J. Unravelling the Improved Electronic and Structural Properties of Methylammonium Lead lodide Deposited from Acetonitrile. Chem. Mater. 2018, 30 (21), 7737-7743. https://doi.org/10.1021/acs.chemmater.8b03084.

(21) Tidhar, Y.; Edri, E.; Weissman, H.; Zohar, D.; Hodes, G.; Cahen, D.; Rybtchinski, B.; Kirmayer, S. Crystallization of Methyl Ammonium Lead Halide Perovskites: Implications for Photovoltaic Applications. J. Am. Chem. Soc. 2014, 136 (38), 13249-13256. https://doi.org/10.1021/ja505556s.

(22) Mosconi, E.; Ronca, E.; De Angelis, F. First-Principles Investigation of the $\mathrm{TiO}_{2} /$ Organohalide Perovskites Interface: The Role of Interfacial Chlorine. J. Phys. Chem. Lett. 2014, 5 (15), 2619-2625. https://doi.org/10.1021/jz501127k.

(23) Grancini, G.; Marras, S.; Prato, M.; Giannini, C.; Quarti, C.; De Angelis, F.; De Bastiani, M.; Eperon, G. E.; Snaith, H. J.; Manna, L.; et al. The Impact of the Crystallization Processes on the Structural and Optical Properties of Hybrid Perovskite Films for Photovoltaics. J. Phys. Chem. Lett. 2014, 5 (21), 3836-3842. https://doi.org/10.1021/jz501877h.

(24) Jeon, N. J.; Noh, J. H.; Kim, Y. C.; Yang, W. S.; Ryu, S.; Seok, S. I. Solvent Engineering for HighPerformance Inorganic-Organic Hybrid Perovskite Solar Cells. Nat. Mater. 2014, 13 (9), 897-903. https://doi.org/10.1038/nmat4014.

(25) Cao, J.; Jing, X.; Yan, J.; Hu, C.; Chen, R.; Yin, J.; Li, J.; Zheng, N. Identifying the Molecular Structures of Intermediates for Optimizing the Fabrication of High-Quality Perovskite Films. J. Am. Chem. Soc. 2016, 138 (31), 9919-9926. https://doi.org/10.1021/jacs.6b04924.

(26) Wu, Y.; Islam, A.; Yang, X.; Qin, C.; Liu, J.; Zhang, K.; Peng, W.; Han, L. Retarding the Crystallization of $\mathrm{Pbl}_{2}$ for Highly Reproducible Planar-Structured Perovskite Solar Cells via Sequential Deposition.

Energy Environ. Sci. 2014, 7 (9), 2934-2938. https://doi.org/10.1039/C4EE01624F.

(27) Miyamae, H.; Numahata, Y.; Nagata, M. The Crystal Structure of Lead(II) lodideDimethylsulphoxide(1/2), $\mathrm{PbI}_{2}(\mathrm{DMSO})_{2}$. Chem. Lett. 1980, 9 (6), 663-664. https://doi.org/10.1246/cl.1980.663.

(28) Wakamiya, A.; Endo, M.; Sasamori, T.; Tokitoh, N.; Ogomi, Y.; Hayase, S.; Murata, Y. Reproducible Fabrication of Efficient Perovskite-Based Solar Cells: X-Ray Crystallographic Studies on the Formation of $\mathrm{CH}_{3} \mathrm{NH}_{3} \mathrm{Pbl}_{3}$ Layers. Chem. Lett. 2014, 43 (5), 711-713. https://doi.org/10.1246/cl.140074.

(29) Petrov, A. A.; Sokolova, I. P.; Belich, N. A.; Peters, G. S.; Dorovatovskii, P. V.; Zubavichus, Y. V.; Khrustalev, V. N.; Petrov, A. V.; Grätzel, M.; Goodilin, E. A.; et al. Crystal Structure of DMFIntermediate Phases Uncovers the Link Between $\mathrm{CH}_{3} \mathrm{NH}_{3} \mathrm{Pbl}_{3}$ Morphology and Precursor's Stoichiometry. J. Phys. Chem. C 2017, 121 (38), 20739-20743. https://doi.org/10.1021/acs.jpcc.7b08468.

(30) Fateev, S. A.; Petrov, A. A.; Khrustalev, V. N.; Dorovatovskii, P. V.; Zubavichus, Y. V.; Goodilin, E. A.; Tarasov, A. B. Solution Processing of Methylammonium Lead lodide Perovskite from $\gamma^{-}$ Butyrolactone: Crystallization Mediated by Solvation Equilibrium. Chem. Mater. 2018, 30 (15), 52375244. https://doi.org/10.1021/acs.chemmater.8b01906.

(31) Paek, S.; Schouwink, P.; Athanasopoulou, E. N.; Cho, K. T.; Grancini, G.; Lee, Y.; Zhang, Y.; Stellacci, F.; Nazeeruddin, M. K.; Gao, P. From Nano- to Micrometer Scale: The Role of Antisolvent Treatment on High Performance Perovskite Solar Cells. Chem. Mater. 2017, 29 (8), 3490-3498. https://doi.org/10.1021/acs.chemmater.6b05353.

(32) Shi, D.; Adinolfi, V.; Comin, R.; Yuan, M.; Alarousu, E.; Buin, A.; Chen, Y.; Hoogland, S.; Rothenberger, A.; Katsiev, K.; et al. Low Trap-State Density and Long Carrier Diffusion in Organolead Trihalide Perovskite Single Crystals. Science 2015, 347 (6221), 519-522.

https://doi.org/10.1126/science.aaa2725. 
(33) Zhang, Y.; Gao, P.; Oveisi, E.; Lee, Y.; Jeangros, Q.; Grancini, G.; Paek, S.; Feng, Y.; Nazeeruddin, M. K. $\mathrm{Pbl}_{2}$-HMPA Complex Pretreatment for Highly Reproducible and Efficient $\mathrm{CH}_{3} \mathrm{NH}_{3} \mathrm{Pbl}_{3}$ Perovskite Solar Cells. J. Am. Chem. Soc. 2016, 138 (43), 14380-14387. https://doi.org/10.1021/jacs.6b08347.

(34) Zhi, L.; Li, Y.; Cao, X.; Li, Y.; Cui, X.; Ci, L.; Wei, J. Perovskite Solar Cells Fabricated by Using an Environmental Friendly Aprotic Polar Additive of 1,3-Dimethyl-2-Imidazolidinone. Nanoscale Res. Lett. 2017, 12 (1), 632. https://doi.org/10.1186/s11671-017-2391-3.

(35) Li, W.; Fan, J.; Li, J.; Mai, Y.; Wang, L. Controllable Grain Morphology of Perovskite Absorber Film by Molecular Self-Assembly toward Efficient Solar Cell Exceeding 17\%. J. Am. Chem. Soc. 2015, 137 (32), 10399-10405. https://doi.org/10.1021/jacs.5b06444.

(36) Manser, J. S.; Saidaminov, M. I.; Christians, J. A.; Bakr, O. M.; Kamat, P. V. Making and Breaking of Lead Halide Perovskites. Acc. Chem. Res. 2016, 49 (2), 330-338. https://doi.org/10.1021/acs.accounts.5b00455.

(37) Stewart, R. J.; Grieco, C.; Larsen, A. V.; Doucette, G. S.; Asbury, J. B. Molecular Origins of Defects in Organohalide Perovskites and Their Influence on Charge Carrier Dynamics. J. Phys. Chem. C 2016, 120 (23), 12392-12402. https://doi.org/10.1021/acs.jpcc.6b03472.

(38) Stamplecoskie, K. G.; Manser, J. S.; Kamat, P. V. Dual Nature of the Excited State in OrganicInorganic Lead Halide Perovskites. Energy Environ. Sci. 2015, 8 (1), 208-215. https://doi.org/10.1039/C4EE02988G.

(39) Seok, S. I.; Grätzel, M.; Park, N.-G. Methodologies toward Highly Efficient Perovskite Solar Cells. Small 2018, 14 (20), 1704177. https://doi.org/10.1002/smll.201704177.

(40) Rahimnejad, S.; Kovalenko, A.; Forés, S. M.; Aranda, C.; Guerrero, A. Coordination Chemistry Dictates the Structural Defects in Lead Halide Perovskites. ChemPhysChem 2016, 17 (18), 2795-2798. https://doi.org/10.1002/cphc.201600575.

(41) Cao, X. B.; Li, C. L.; Zhi, L. L.; Li, Y. H.; Cui, X.; Yao, Y. W.; Ci, L. J.; Wei, J. Q. Fabrication of High Quality Perovskite Films by Modulating the $\mathrm{Pb}-\mathrm{O}$ Bonds in Lewis Acid-Base Adducts. J. Mater. Chem. A 2017, 5 (18), 8416-8422. https://doi.org/10.1039/C7TA00539C.

(42) Yoon, S. J.; Stamplecoskie, K. G.; Kamat, P. V. How Lead Halide Complex Chemistry Dictates the Composition of Mixed Halide Perovskites. J. Phys. Chem. Lett. 2016, 7 (7), 1368-1373. https://doi.org/10.1021/acs.jpclett.6b00433.

(43) Mastria, R.; Colella, S.; Qualtieri, A.; Listorti, A.; Gigli, G.; Rizzo, A. Elucidating the Effect of the Lead lodide Complexation Degree Behind the Morphology and Performance of Perovskite Solar Cells. Nanoscale 2017, 9 (11), 3889-3897. https://doi.org/10.1039/C6NR09819C.

(44) Masi, S.; Aiello, F.; Listorti, A.; Balzano, F.; Altamura, D.; Giannini, C.; Caliandro, R.; Uccello-Barretta, G.; Rizzo, A.; Colella, S. Connecting the Solution Chemistry of $\mathrm{PbI}_{2}$ and MAl: A Cyclodextrin-Based Supramolecular Approach to the Formation of Hybrid Halide Perovskites. Chem. Sci. 2018, 9 (12), 3200-3208. https://doi.org/10.1039/C7SC05095J.

(45) Sharenko, A.; Mackeen, C.; Jewell, L.; Bridges, F.; Toney, M. F. Evolution of lodoplumbate Complexes in Methylammonium Lead lodide Perovskite Precursor Solutions. Chem. Mater. 2017, 29 (3), 13151320. https://doi.org/10.1021/acs.chemmater.6b04917.

(46) Frisch, M. J.; Trucks, G. W.; Schlegel, H. B.; Scuseria, G. E.; Robb, M. A.; Cheeseman, J. R.; Scalmani, G.; Barone, V.; Petersson, G. A.; Nakatsuji, H.; et al. Gaussian 09, Revision D. 01; Gaussian, Inc., Wallingford CT, 2016.

(47) te Velde, G.; Bickelhaupt, F. M.; Baerends, E. J.; Fonseca Guerra, C.; van Gisbergen, S. J. A.; Snijders, J. G.; Ziegler, T. Chemistry with ADF. J. Comput. Chem. 2001, 22 (9), 931-967. https://doi.org/10.1002/jcc.1056.

(48) Fonseca Guerra, C.; Snijders, J. G.; te Velde, G.; Baerends, E. J. Towards An Order-N DFT Method. Theor. Chem. Acc. 1998, 99 (6), 391-403. https://doi.org/10.1007/s002140050353.

(49) ADF 2014, SCM, Theoretical Chemistry, Vrije Universiteit, Amsterdam, The Netherlands, http://www.scm.com.

(50) van Lenthe, E.; Baerends, E. J.; Snijders, J. G. Relativistic Regular Two-Component Hamiltonians. J. Chem. Phys. 1993, 99 (6), 4597-4610. https://doi.org/10.1063/1.466059. 
(51) Wang, F.; Ziegler, T.; van Lenthe, E.; van Gisbergen, S.; Baerends, E. J. The Calculation of Excitation Energies Based on the Relativistic Two-Component Zeroth-Order Regular Approximation and TimeDependent Density-Functional with Full Use of Symmetry. J. Chem. Phys. 2005, 122 (20), 204103. https://doi.org/10.1063/1.1899143.

(52) Becke, A. D. Density-Functional Thermochemistry. III. The Role of Exact Exchange. J. Chem. Phys. 1993, 98 (7), 5648-5652. https://doi.org/10.1063/1.464913.

(53) Stephens, P. J.; Devlin, F. J.; Chabalowski, C. F.; Frisch, M. J. Ab Initio Calculation of Vibrational Absorption and Circular Dichroism Spectra Using Density Functional Force Fields. J. Phys. Chem. 1994, 98 (45), 11623-11627. https://doi.org/10.1021/j100096a001.

(54) Nunzi, F.; De Angelis, F.; Selloni, A. Ab Initio Simulation of the Absorption Spectra of Photoexcited Carriers in $\mathrm{TiO}_{2}$ Nanoparticles. J. Phys. Chem. Lett. 2016, 7 (18), 3597-3602. https://doi.org/10.1021/acs.jpclett.6b01517.

(55) Nunzi, F.; Fantacci, S.; Cariati, E.; Tordin, E.; Casati, N.; Macchi, P. Stabilization Through PDimethylaminobenzaldehyde of a New NLO-Active Phase of [E-4-(4-Dimethylaminostyryl)-1Methylpyridinium] lodide: Synthesis, Structural Characterization and Theoretical Investigation of Its Electronic Properties. J. Mater. Chem. 2010, 20 (36), 7652-7660. https://doi.org/10.1039/c0jm00466a.

(56) ReactLab Equilibria | Jplus Consulting http://jplusconsulting.com/products/reactlab-equilibria/ (accessed Apr 10, 2017).

(57) Hamill, J. C.; Schwartz, J.; Loo, Y.-L. Influence of Solvent Coordination on Hybrid Organic-Inorganic Perovskite Formation. ACS Energy Lett. 2018, 3 (1), 92-97. https://doi.org/10.1021/acsenergylett.7b01057.

(58) Gutmann, V. Coordination Chemistry of Certain Transition Metal Ions in Donor Solvents. In Coordination Chemistry in Non-Aqueous Solutions; Gutmann, V., Ed.; Springer Vienna: Vienna, 1968; pp 161-168.

(59) Shimoni-Livny, L.; Glusker, J. P.; Bock, C. W. Lone Pair Functionality in Divalent Lead Compounds. Inorg. Chem. 1998, 37 (8), 1853-1867. https://doi.org/10.1021/ic970909r.

(60) Persson, I.; Lyczko, K.; Lundberg, D.; Eriksson, L.; Płaczek, A. Coordination Chemistry Study of Hydrated and Solvated Lead(II) Ions in Solution and Solid State. Inorg. Chem. 2011, 50 (3), 10581072. https://doi.org/10.1021/ic1017714.

(61) Gritzner, G. A Critical View on the Lewis-Donor (Nucleophilic) Properties of Solvents. J. Mol. Liq. 1997, 73-74, 487-500. https://doi.org/10.1016/S0167-7322(97)00090-1.

(62) Persson, I.; Sandström, M.; Goggin, P. L. On the Coordinating Properties of Some Solvents. A Vibrational Spectroscopic Study of Mercury(II) Halides and Antimony(V) Chloride in Solution; New Concepts for Lewis Basicity Scales of Solvents. Inorganica Chim. Acta 1987, 129 (2), 183-197. https://doi.org/10.1016/S0020-1693(00)86662-1.

(63) Munakata, M.; Kitagawa, S.; Miyazima, M. Classification of Solvents Based on Their Coordination Power to Nickel(II) Ion. A New Measure for Solvent Donor Ability. Inorg. Chem. 1985, 24 (11), 16381643. https://doi.org/10.1021/ic00205a009.

(64) Munakata, M.; Kitagawa, S. Coordination Power Series of Solvents: 2. The Solvent Effects on Complex Formations, Half-Wave Potentials, ${ }^{113} \mathrm{Cd}$ NMR Resonances and Gibbs Free Energy Changes of Transfer. Inorganica Chim. Acta 1990, 169 (2), 225-234. https://doi.org/10.1016/S00201693(00)80522-8.

(65) Stevenson, J.; Sorenson, B.; Subramaniam, V. H.; Raiford, J.; Khlyabich, P. P.; Loo, Y.-L.; Clancy, P. Mayer Bond Order as a Metric of Complexation Effectiveness in Lead Halide Perovskite Solutions. Chem. Mater. 2017, 29 (6), 2435-2444. https://doi.org/10.1021/acs.chemmater.6b04327.

(66) Fawcett, W. R. Acidity and Basicity Scales for Polar Solvents. J. Phys. Chem. 1993, 97 (37), $9540-$ 9546. https://doi.org/10.1021/j100139a045. 
Table of Contents

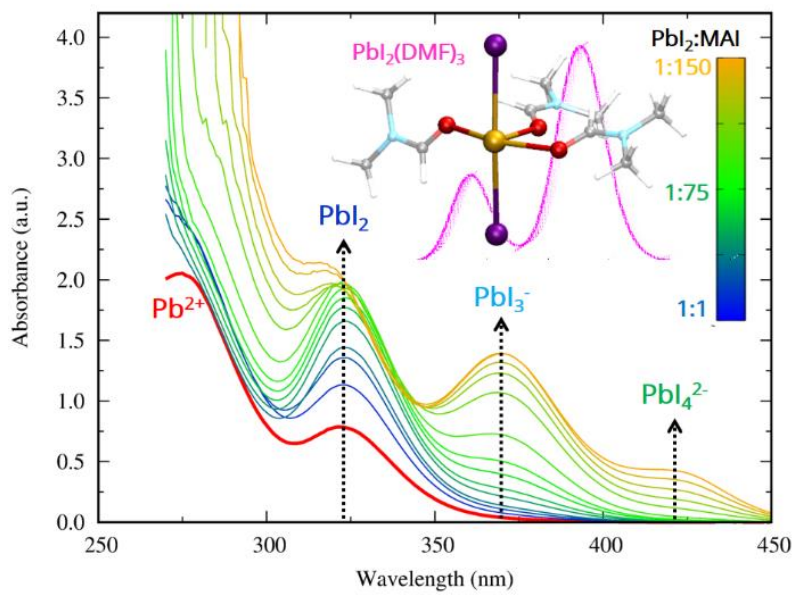

